\title{
Application of Project Teaching Method in Machine Tool Electric Control Technology
}

\author{
Mao Yin \\ School of Mechanical Engineering Dalian Vocational \& Technical College Dalian, China.
}

mydxyx_2011@163.com

Keywords: Project teaching method; Machine tool electric control technology; Teaching application;

\begin{abstract}
In the machine tool electric control technology teaching, the traditional teaching mode is relatively single. There are low student participation, low students enthusiasm, poor practice ability and so on a variety of disadvantages. In this paper, through the actual case to introduce a new method of teaching-project teaching method. In this teaching process students complete the project independently. The teacher only play the role of guidance in the process of design. The teacher finish the teaching task of the new curriculum through the new teaching method. Eventually to improve students' comprehensive quality and practical application ability.
\end{abstract}

\section{Introduction}

Along with the rapid development of modern industrial control fields, electrical control technology, as one of the important ways to realize industrial production automation has gradually turned into one of three big pillars of modern industrial control fields. Machine tool electrical control is integrating mechanical and electrical professional technology curriculum in vocational colleges. At the same time, it is also the basis of the electrical control technology important subject. The course integrating theoretical knowledge and practical operation. It is closely linked with everyday life and actual production work. So it is an important basic subject in the field of modern industrial control. But the course involves many complicated subject knowledge. It need a lot of operation and high professional qualification. So there is a big difficulty in the actual teaching process. In the process of traditional teaching, the teacher give students a lesson about electrical knowledge. Ignoring the cultivation of the students ability to solve problems and engineering application ability. This teaching method lead to students' weak practical ability. Students can't take in the theory application in the actual production work flexible ${ }^{[1]}$. In order to combine theoretical knowledge and practical operation, it need to change the teaching method. So this article introduces a new teaching method named project teaching method. This teaching method can make students learning in practice, have fun in learning, and thinking in the play. Through this kind of teaching method it can cultivate students' interest in study and the confidence of the practice.

\section{Problems Existing in the Traditional Teaching Process[2]}

The Traditional Single Teaching Method Apply to Part of the Students. Because of the students' individual level differences, single curriculum can only meet the needs of part of the students, lack of teaching and guiding to all of the students. In the teaching process, the students who have interest in the course and own high skills can easily master the knowledge. But the other students who have low interest in the course can not accept the new knowledge. This part of the students can't keep up with the teaching progress. It need rely on the help of the teacher or classmate to complete the study task.

The Traditional Teaching Method Can't Exert Students' Subjective Initiative. In the process of the traditional teaching , the teacher let the students master the new knowledge by means of treating all the students on the same content. Most of the time the teacher is speaking and speaking .Teachers are the main characters in the classroom. The students play the role of the 
audience in the classroom. Students lack of independent thinking and hands-on practice opportunities. This way is not conducive to cultivate students' creative ability, subjective initiative and independent thinking ability.

The Traditional Teaching Method of the Evaluation Process is One-Sided. The course that named the machine tool electrical control is a strong practical courses. But the traditional evaluation process mainly through written test students' theoretical level. It lack of the step to check the students' practical operation ability. So it can't accurately test the students accurate level on this course.

\section{Design Principles of the Project Teaching Method}

The project teaching method is a teaching process that the student through self-study and find information to complete the project plan independently. In the teaching process, students need to complete the project which the teacher gives by themselves. The students need to learn the relevant knowledge combined with the project requirements, solve varieties of problems they get. The teacher needs to play an important role in the teaching process. The teacher doesn't take part in the project design process. The teacher need to give advice, direction and new knowledge to students when they need your help. In this way, it can improve the students' independent operation ability. It need to follow the following principles in order to improve the feasibility and operability ${ }^{[3]}$.

Comprehensive Content of the Project. The teacher need to provide accurate project requirement and comprehensive teaching content which contains all the associated knowledge. He need to change the traditional teaching arrangement, design a project that contains all the teaching contents and requirements. For example, the teaching content is the basic instruction of PLC. It need to contain car straight line reciprocating movement, alarm lights, buzzer, traffic lights, etc. In the operating skills, it requires students to master PLC circuit connection, application of writing, debugging and so on.

Participation in the Process of the Project. The project teaching method change the traditional teaching method that the teacher talk and the student listen. The students' attitude change from passive to positive.Teachers turn into a guide in the teaching process gradually. At the same time, we can divide students into different groups according to students' specialty. It can improve the students' sense of responsibility and unity cooperation ability by the way of cooperation.

The Richness of Project Results. The project teaching design can be the design of a product, correct a failure, complete a project, provide a service and so on. Therefore, the outcome of the project teaching method should be diversified. It can use different projects in the same course . The results reflect form can also be different in the same item. Such as: the project of music fountain it need to complete the circuit principle diagram, installation wiring diagram, the program listing, circuit boards, commissioning report, project summary report, etc.

\section{The Application of Project Teaching in this Course}

The project content use the actual production task as a template. It also combined with the teaching requirements which in the national vocational qualification standards. It can meet the requirement of teaching, and at the same time it can conform to the actual work needs. The project teaching method according to the teaching goal and students' cognitive law. It can make the transition from single to comprehensive design project. It can improve students' ability of program design, installation, writing, debugging, and so on. Next, through an example named traffic lights to describe the application of this teaching method in teaching process ${ }^{[4]}$.

Establishment Situation, Puts Forward the Project Tasks. The teacher show the working process of the traffic lights by playing the multimedia courseware. Make the students understand the project task clearly. It required the students use the knowledge of the PLC control to design the traffic lights. Traffic signals are divided into two groups. One group of signal light is located in the north-south direction. Another set of signal light is located in the east-west direction. Lights include red, yellow, and green three colors. When the switch start to work, the traffic signal system begin to 
work, the light which located in the north-south direction turn red and keep seven seconds, the light which located in the east-west direction turn green and keep five seconds. In the fifth seconds the light located in the east-west direction need to turn to yellow and keep two seconds, then, it need to turn to red and keep seven seconds. While the light located in the east-west direction turn to red, the other signal light need turn to green and keep five seconds, in the fifth seconds it need to turn to yellow and keep two seconds, then, it turn to red and keep seven seconds. Two groups of signal cycle these steps. When the switch stop to work, the traffic signal system stop to work at the same time.

Set Grouping and Collecting Data. After decorating the project task, the teacher divided students into groups combined with the students' characteristics. Each group have five students , and need to determine a team leader. Next they should design the project by themselves. The group leader assigned tasks and lead team members to carry out the project design through the student, collecting related information alone. Teachers guide students to analyze traffic lights sequence diagrams, such as inspire the student to use auxiliary relay $\mathrm{M}$ or state relay $\mathrm{S}$ order control method to achieve control. The students should study activity, finish the project by themselves.

The Design of Scheme Selection. In the process of program design, when students meet difficulties, the teacher should put forward the new knowledge point named the sequential design control method .According to the working process of the system the students finish drawing the sequential function chart, then according to the sequence function diagram design a ladder diagram method. In the process the teacher complete the teaching goal of the new knowledge, at the same time improve the students' ability to analyze and solve problems. The teacher play the role of a guide all the time. For example: prompt students can't choose blindly on the selection of the timer problem. Finally complete the project through the student s' efforts and the teachers' guide.

Plan Implementation. After determined the design project, it need to run the program debugging, analyze feasibility of the project. In the process of debugging, let the students observe, perceive and contrast, develop the students' ability of insight. When the program running wrong, teachers should guide students to analyze problems in time, accumulate experience, correct mistakes, and let the student complete the project. The students achieve success through their efforts step by step. In the repeated debugging process, improve the students' sense of pride and accomplishment, cultivate the students' self-confidence and creation ability, improve students' ability to analyze and solve problems.

Performance Evaluation and Project Summary. Teachers need to calculate students' actual total score according to the project inspection standards. The main assessment content should include terminal connection, the $\mathrm{I} / \mathrm{O}$ address allocation, sequence function diagram design, programming, debugging process and operation, project reports as requested to complete and correct, safety civilization consciousness, the spirit of unity and cooperation, and so on. The performance evaluation will be divided into three parts. First, students give the score by themselves according to the grading standard. Next, students give the score by each other. Find the problem and put forward the improvement opinion from the perspective of students. Teachers should guide students to give objectively evaluating each other .Through this process make students understand their own advantages and disadvantages, learn other student's special features and advantages to improve themselves. Third, the teacher give evaluation according to the completion of the project ${ }^{[5]}$. Finally the teacher need to combine three parts performance score to make a comprehensive evaluation of each student. After complete the project, the teacher recognition performance outstanding team and work. The teacher help the unfinished task team to find reasons and put forward improvement suggestion.

\section{The Influence of Using Project Teaching Method}

Through the project teaching method it can complete imparting new knowledge in the process of project design .It can also stimulate students learning initiative and enthusiasm, cultivate the students' practice ability, improve the students' comprehensive quality. The effect of the project teaching method reflects in the following respects. 
Stimulate Students' Learning Interest and Enthusiasm. Issued project teaching can inspire students' initiative and enthusiasm of project design. Students can study, collect information and seek the solution independently. It can change passive learning into active learning. Students can learn new knowledge in the project, at the same time students can find pleasure in learning .

Cultivate the Students' Comprehensive Quality and Practical Ability. Project teaching method in which students by completing different projects of software and hardware design, installation, wiring and debugging tasks, the students can master the general design method of machine tool electrical control system. It can combine theoretical knowledge and practical ability to solve the problem. It can not only improve the level of theoretical knowledge, but also improve the ability of engineering practice application.

Cultivate the Students' Team Cooperation Ability. In the traditional teaching, the students finish learning in the classroom alone, lack of cooperation process. In the project teaching process, students complete the project design by team members discussing together. During the discussion it can improve students' cooperation ability, sense of honor and responsibility. It can lay a good foundation for students to be going to work in the future.

\section{Conclusion}

The effect of project teaching method, not only improve the effect of the education, but also improve the students' ability to analyze and solve problems. It reflected the teachers' leading role and played a major role of students. It embodies the patterns and characteristics of vocational education teaching. Through practice it proved that the project teaching method in the teaching of machine tool electrical control is an effective method.

\section{Reference}

[1] Ma Yuling. The application of project teaching method in the PLC course teaching [J]. China's vocational and technical education, 2016 (4) : 54-59

[2] Wang aihua. The project teaching in the application of PLC teaching [J]. Journal of secondary vocational technical education, 2012:25-26

[3] Guo Yu. Flip classroom based course "computer application foundation" of mechanic college teaching reform to explore [J]. Guangdong mechanic education research, 2014 (4)

[4] Gong deng, Han Gang,Su Chuanjun. Diverse teaching method in "CNC machine electrical control and PLC" course application [J]. Journal of wuyi university journal, 2015 (3) : 103-105

[5] Jia Jia. The application of project teaching method in the PLC course teaching [J]. Journal of information technology education and research, 2016:124-125 